\title{
Performance Measurement Model for Moroccan Automotive Suppliers Using PMQ and AHP
}

\author{
Mohamed Tarek CHAHID ${ }^{1,4}$, Jamila EL ALAMI ${ }^{2}$, Aziz SOULHI ${ }^{3}$ \& Nouredine EL ALAMI ${ }^{1}$ \\ ${ }^{1}$ University Mohammed V-Agdal, Mohammadia School of Engineers, Rabat, Morocco \\ ${ }^{2}$ University Mohammed V-Agdal, Superior School of Technology Sale, Sale, Morocco \\ ${ }^{3}$ National School of Mineral Industry, Rabat, Morocco \\ ${ }^{4}$ Moroccan Institute for Training in Automotive Industry (IFMIAC), Casablanca, Morocco \\ Correspondence: Mohamed Tarek CHAHID, Institut de Formation aux Métiers de l'Industrie Automobile de \\ Casablanca, Voie EC 03, Nouvelle Zone Industrielle - Ahl Loughlam - Sidi Bernoussi, BP 1152 Casablanca, \\ Morocco. Tel: 212-529-028-865. E-mail: t.chahid@giac1.org
}

Received: August 24, 2014

doi:10.5539/mas.v8n6p137

\author{
Accepted: August 29, $2014 \quad$ Online Published: October 18, 2014 \\ URL: http://dx.doi.org/10.5539/mas.v8n6p137
}

\begin{abstract}
This research aims to develop a Performance Measurement model for Moroccan automotive suppliers. The study is done in two steps: First, it derives Key Performance Indicators (KPI) from the Performance Measurement Questionnaire (PMQ) and matches their weights by the Analytical Hierarchy Process (AHP). Then, the latter two are applied to build an overall performance formula for these companies. The findings of this work show that the Moroccan automotive suppliers consider the efficiency of the production system and the development of the Human skills as the foremost priority. Also, the global performance formula integrated others dimensions such as safety at work and favorable social climate. This finding should integrate strategies and policies for the decision makers in the Moroccan automotive sector.
\end{abstract}

Keywords: Performance Measurement model, global performance formula, Appropriate Key Performance Indicators (AKPI), Performance Measurement Questionnaire (PMQ), AHP, Moroccan automotive suppliers

\section{Introduction}

The automotive industry must deliver world class products according to highly competitive market requirements; and for the industry's survival, it has to be flexible, proactive, responsive, and cost competitive. To evaluate its achievement, the manufacturers adopt continuous performance measurements (PM) as key drivers of performance (RAHMAN et al., 2010). However, over the years the industrial accounting has been based on a cost accounting exercise that have failed to integrate all the critical factors of manufacturing success; the actual environment demands more accurate and different measures of performance (Kennerley and Neely, 2003).

Eccles (1991) argues that the measurement systems must show how a company is doing compared with its current competitors, not with its own practice, on one hand. And on the other hand the new requirements of Performance measurements (PM) treat the cost, quality and delay dimensions as just elements of expansive set of measures rather than main measures (Carr and Hassan, 2008). Also, PM helps managers to exploit the productivity deposit to reach better organizational goals (Eswaramurthi and Mohanram, 2013).

Manufacturing performance measurement in the automotive industry is important in emerging countries, especially in Morocco, which is considered as the best delivery platform for the European market with over 120 equipment manufacturers, producing near the amount of $€ 2500$ million, and employing 60000 employees resulting in the part of exported production value at over $90 \%$ (AMICA, 2012).

To date, there are no a performance measurement study or model developed in morocco (AMICA, 2012), so we propose a systematic scoring method for all Key Performance Indicators (KPI) in order to establish a performance measurement model that reflects the main characteristics of the Moroccan automotive suppliers.

Our intention was to develop a management performance model for the Moroccan automotive industry. The propositions of this manuscript initiated from the manufacturers' demand for an assistance to better understand the factors of success or the roots of deficiency of Moroccan automotive suppliers and to monitor strategic action 
plans.

First, this article will illustrate the definitions and the tools for the developed PMS model from the literature review. Then, it will give the process followed to develop the framework for the performance measurement. And last, it presents a complete numerical example by evaluating a Moroccan automotive supplier using the developed model; the results and analysis of the application, and conclusions.

\subsection{Performance Measurement System}

In their continuous improvement process, the manufacturing companies' performance depends mainly on their production process; the use of performance measurement has become an important area of research in the industry and academia alike to the extent that firms invest more human and material resources to measure their performance (Aracioglu et al., 2013).

In a global and competitive market, manufacturing companies face more stringent customer requirements, prompting them to be more responsive to these needs which include increasingly varied and numerous specifications with more flexible processes, coordination between resources and suppliers throughout the supply chain to reduce costs. In order to accomplish this, the management should integrate performance data in their overall corporate management (Nudurupati et al., 2011). This integration is done through business strategy, internal organization, and the external environment. It is done by the control and adjustment of the current values of the performance against desired performance levels (Melnyk et al., 2014).

The etymology of the word "Measure" suggests that the performance measurement system should be balanced. i.e. it should include the indicators necessary and sufficient for decision making rather than drawing all the outlines of the performance (Micheli and Mari, 2014).

In the area of business research; the concept of performance is still the least ambiguous. The researcher's intuition is the beginning of any exploration in this area (Folan et al., 2007).

A major problem in the design of a performance measurement system concerns the determination of expressions of performance that are useful for decision-making. In fact, the distinction should be made between the overall objectives of the organization; which are broken down along organizational levels (Ducq et al.; 2001).

Any given Performance Measurement System (PMS) should make an improvement in internal processes, give a precise comprehension of customer requirements, and help the implantation of the strategic operations management system, conferring improvements in operational efficiency and overall business effectiveness (De Lima et al., 2013).

The performance of the manufacturing system (cost, quality, delivery and flexibility...) is determined by the configuration of equipments, manpower, data flows, process and technology, this configuration give manufacturers competitive advantages (Bititci et al., 2001). So the company's performance is determined by its ability to achieve the objectives set by the business strategy (Michalska, 2005).

Braz et al. (2011) suggest that good performance measures are quantitative, objective, and not subjective. They are simple, understandable, practical, and consistent with appropriate scales and clear objectives over time. Also, their multidimensionality defines the inputs and outputs of the important processes.

A successful PMS requires structural and procedural frameworks, in addition to other performance management tools (Folan and Browne, 2005). According to Neely et al. (1996), the design of PMS should be easier, if we:

1. Choose what we should measure

2. Choose how we are going to measure

3. Amass the fitting data

4. Eradicate divergence between measurement indicators

Otherwise, Folan and Browne (2005) propose that performance measurement should:

- Be material

- $\quad$ Be closer to the customer

- Be supported by top management

- Engage human resources in their progress

- Ensure that these measures are applied in daily tasks

- Be component of a regulation loop 
- Principally exploit non-financial performance indicators

- Adjust as the corporation requests change

- Be wished-for promoting improvement

Melnyk et al. (2013) give the definitions below:

- Performance Measure (PM) is the tool used to measure the efficiency and/or effectiveness of work, therefore, a performance measure is both quantifiable and verifiable.

- The metric has three distinctive fundamentals:

1. A performance measure quantifies what is happening

2. A performance objective indicates what is considered high and low performance so assists the management.

3. The results provide assurance to be under or on top of the target

Although a measure is instructive, a metric is critical from a business perspective. All three elements are crucial; deleting any one of these elements paralyzes the metrics and reduces its effectiveness.

- Metric sets are used to conduct and manipulate the actions of human resources, teams, functions. Metric sets are numeral limited.

The main goal of PMS is to transform the data measurement into information to assess the effectiveness and efficiency of action. It is in fact the establishment of objectives, collect, analysis and interpretation of performance measures. On the other hand, The system should function as a thermostat, in a way that the process aim to evaluate the inequality between the actual result and the target, to identify those critical inequalities, to appreciate the roots of dysfunctions in order to introduce corrective and preventive actions (Melnyk et al., 2013).

To make a decision, all expressions of performance must be treated to compare different situations that occur in the industrial context. Therefore, two types of performance expressions are involved in a PMS: Elementary expressions that identify degrees reached different objectives, and the aggregate expressions that are the synthesis of elementary performance expressions in the overall objectives. Also, aggregation expressions define the priorities in the strategy and give the choice of the two scenarios based on their expressions of basic performance (Clivelle et al., 2006).

Concerning the PMS design, the practices in the industry followed methodologies that link strategic objectives, tactical and operational factors affecting them, by designing associated performance expressions (Neely 99). Bititci et al. (2001) express PMS as an information system that is used to supervise performance, identify critical areas, enhance motivation, improve communication and strengthen accountability. Kaplan and Norton introduced the balanced scorecard approach to measure performance following four perspectives (customer, internal business process, financial and learning) of a company (Kaplan and Norton, 1996).

The activity based costing $(\mathrm{ABC})$ model categorizes the activities and processes only by added value in the company (Brimson, 1991). Also, the process performance measurement system (PPMS) utilizes five aspects (finance, innovation, customer, societal and employee) to measure the company performance (Kueng and. Krahn, 1999). The ECOGRAI method adopts three sides (delay, quality and cost) for the expression of multicriteria performance.

However, Berrah et al (2004) showed that PMS's usually cover the following main points:

- The definition of the company area concerned by the PMS.

- The expression of the decomposition links between the strategic objectives and the elementary objectives

- The definition of the way in which the associated "elementary" performances are expressed (physical measure, performance measure, performance evaluation).

- The choice of the aggregation tools used to obtain global performance expression.

More specifically, in a few existing PMS, analytical methods are used to quantify the objective breakdown and the performance aggregation steps. First, the Key Success Factors are identified. Elementary performance expressions are then established as well as the coupled weights. These weights quantify the hierarchical links of the elementary expressions. The global performance expression results from the aggregation, by the weighted arithmetic mean (WAM) operator (Berrah et Clivelle, 2007). 


\subsection{The Use of KPI}

Key Performance Indicators (KPIs) represent a set of measures focusing on those aspects of organizational performance that are the most critical for the current and future success of the organization or Key Success Factors (KSF) (Parmenter, 2007). The performance measurement process includes a type of measure that is writing into a ratio, being linked to a target point. This target point is called the objective (Berrah and Foulloy, 2013).

In order to establish their performance measurement, organizations formulate Key Performance Indicators (KPIs) (e.g., number of clients, costs...) that are considered essential, adequately expressive, and representative for the state and organization's cap (Popova and Sharpanskykh, 2011). Performance measurement systems based on KPIs are coupled to the organization's strategy (Franco-Santos et al., 2012).

PMS defines objectives resulting from strategy. The different measures collected by the KPIs notify if the goals they are connected to are being reached or not, according to an ascending process (Rodriguez et al., 2010).

Popova and Sharpanskykh (2011) describe a clear method to institute a link between KPIs and goals; they introduce the notion of an "Achievement Level" or goal pattern. The performance of an organization can be evaluated by estimating the (level of) satisfaction of its goals.

Each KPI has its individual metrics. So we have to introduce the commensurability and meaningfulness of these metrics. Performance sets should ideally be defined without any unit to guarantee commensurability. The measured values are homogeneous for the meaningfulness (Marques et al., 2010).

According to Clivelle et al. (2006), the commensurability and meaningfulness aim to improve the coherence of information on one side, and on the other side make the determination of aggregated expressions from the elementary performances easier. Also, this Development should be understood as a coordination effort rather than a design effort (Lohman and Fortuin, 2004).

\subsection{The Use of PMQ}

The Performance Measurement Questionnaire (PMQ) helps managers to recognize the improvement requirements of their business, and to create a schedule for them. It provides a method for identifying the improvement areas and their coupled performance measures (Ghalayini et al., 1997).

The PMQ is used to develop the corporate orientations, supporting factors of success and linked performance measures. The PMQ is distributed to top management, plant management, and process improvement team leaders. The plant management and process improvement team leaders are integrated to guarantee that the particular needs of each plant are met (Ghalayini et al., 1997).

Once the PMQ results were indexed, the interpretation of results is conducted jointly with company managers (Ghalayini et al., 1997).

The PMQ includes three components:

1. What are the company managers to ask?

2. What is the priority for progress in the long term and what is the pertinence of existing indicators?

3. What are the actual goals and measurements?

\subsection{The Use of AHP}

The AHP is the main utilized tool by researchers and managers in multi criteria decision making. The fields of AHP's use are planning, choosing best scenarios, resource management (Vaidya and Kumar, 2006). AHP can mix different kinds of data in multilevel decision configuration to get a full visualization of the manufacturing organization (Hernandez-Matias et al., 2008).

In scholar literature, over 2000 AHPs applications were counted; they are used when resolutions need quantitative and qualitative aspects (Subramanian and Ramanathan, 2012).

The AHP isn't simply making the resolution of the weights, but also formulates the aggregation of performance expression. In fact, ratio scales are done from human expertise which is a complicated assignment in an industrial context where the performance is mainly relative (Berrah and Clivelle, 2007).

The AHP chooses the fitting measures based on the user's perceived magnitude of the performance perspectives. On the other side, the global performance measurement depends on the policy priorities of performance and indicators proposed by the managers (Grigoroudis et al., 2012). 
The weighted mean, which is the most recurrent conciliation aggregation operator, is commonly used to get the overall performance (Clivelle et al., 2006).

\subsection{QMPMS Model}

The Quantitative Model of Performance Measurement System (QMPMS) makes available an expression of performance to quantify the reach of the overall objective, also the QMPMS method evaluate the global performance and sensitivity of different strategies (Bititci et al., 2001).

According to (Suwignjo et al., 2000), there are three parts in the Quantitative Model for Performance Measurement System (QMPMS):

1. Detection of Key Success Factors (KSF) and their linkage to performance (KPI),

2. Arranging the factors hierarchically

3. Quantifying the effect of the factors on performance and aggregating them into a single dimensionless unit (Global Performance).

In QMPMS, the KPIs are recognized with a tree map. However, the determination of the weights is based on the AHP process. The overall performance expression is the aggregation of elementary indicators, calculated by the weighted arithmetic mean (WAM) operator (Suwignjo et al., 2000).

\section{Methods}

\subsection{Proposed Method}

To develop our model, the existing performance expressions were identified and analyzed by data collected from the Performance Measurement Questionnaire (PMQ) that collects and selects several KPIs. All Appropriate Key Performance Indicators (AKPI) were derived from Key Success Factors (KSF) that are issued from the compilation of strategic orientations of the Moroccan automotive suppliers. Then the AKPI was assigned weights according to the Analytical Hierarchy Process (AHP).

The global performance (GP) is expressed by AKPI's performance $\left(\mathrm{P}_{\mathrm{AKPI}}\right)$ with their appropriate weights; the $\mathrm{P}_{\mathrm{AKPI}}$ is obtained by matching the Achievement Level (AL) through percentage formula value measured of AKPI and the target value. This GP can be used to support decision making tasks for launching new manufacturing strategies.

To accomplish this research's goal, the subsequent methodology (figure1) was performed: 1), we obtained the Key Success Factors (KSF) that are the consequence of disaggregation of the major areas of action in Moroccan automotive industry. The formulation of KSF objectives correspond to Key Success Performance (KSP) that are established through a set of Key Performance Indicators (KPI), so all KPIs used in those plants were collected; 2) Appropriate Key performance Indicators for all the Moroccan Automotive Sector (AKPI) were selected from the Performance Measurement Questionnaire (PMQ); 3) according to the selected indicators( AKPI), a management performance measurement hierarchy was proposed, and the weights of all of the indicators were estimated using an AHP analysis; 4) The quantification by the overall performance is obtained by calculating a weighted mean of all performance expressions associated with the various heterogeneous criteria that are translated into a common reference (achievement level).; 5) the model developed in this study was used and analyzed in Moroccan automotive supplier. 


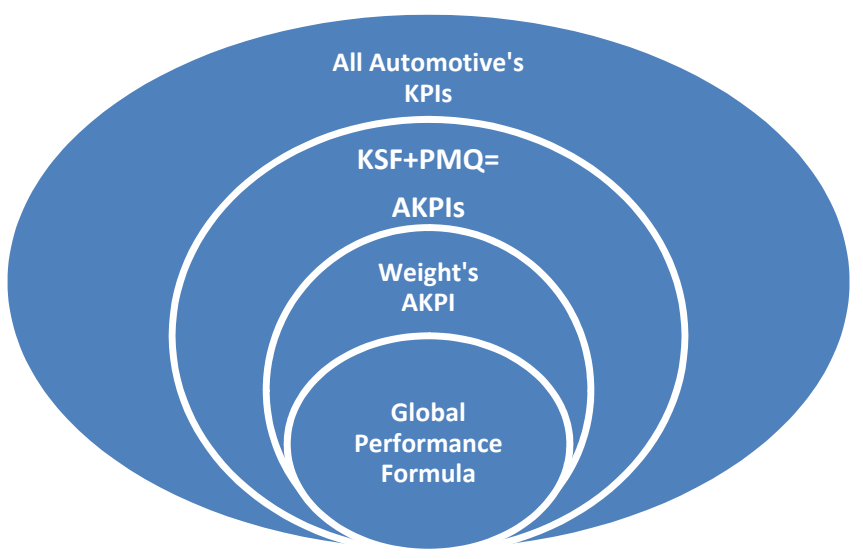

Figure 1. Methodology concept

\subsection{Model Development}

\subsubsection{Matching AKPI}

To reflect the multidimensional aspect of performance, the use of PMQ was utilized to identify improvement areas. The PMQ was administrated during 2012 to 28 Moroccan automotive suppliers from different nationalities (USA, Japan, Germany, Spain, France...) that are employing 25.000 employees.

A total of 24 responses was received 17 of which were usable, yielding the response rate of $61 \%$. The non response bias is a result of the confidentiality of these KPIs.

Key Success Factors (KSF) are defined as the important areas for the company's long assortment success. KSF are based on the organization's strategy and the use of the PMQ.

Once the KSF are matched, all tasks all over the organization are anticipated to measure and improve upon them. The PMQ help managers to identify the improvement needs of their organization, to determine the extent to which the existing performance measures support improvement, and to establish an agenda for performance measure improvements. The outputs of PMQ are used to develop the organizations' strategies, supporting areas of success and appropriate performance measures.

The PMQ allows linkage between KSF and appropriate performance measures for these areas. These factors and measures are determined as a consequence of business strategic planning and the result of the PMQ.

Table 1. List of automotive suppliers interviewed

\begin{tabular}{|c|c|}
\hline \multicolumn{2}{|c|}{$\begin{array}{ll}\text { Company } & \text { Nationality } \\
\text { DELPHI ASM, DELPHI PACKARD, LEAR Automotive Morocco; }\end{array}$} \\
\hline $\begin{array}{l}\text { DELPHI ASM, DELPHI PACKARD, LEAR Automotive Morocco } \\
\text { POLYDESIGN SYSTEMS, SINFA Filtres }\end{array}$ & ;USA \\
\hline SEWS CABIND, SEWS Maroc, YAZAKI, AWSM & Japan \\
\hline $\begin{array}{l}\text { LEONI Ain Sebaa, LEONI Bouznika, Cables Alliance Maroc } \\
\text { SCHLEMMER }\end{array}$ & Germany \\
\hline MANIPULADOS, ANTOLIN, DABELSA Maroc, PLASTEX Maroc & Spain \\
\hline FAURECIA, CFCA, TREROC, CAPELEM, SACRED Maroc & France \\
\hline SILA Maroc & Italy \\
\hline COFICAB & Tunisia \\
\hline SMFN, SIPROF, SINFA Cables, INDUVER & Morocco \\
\hline
\end{tabular}

For the identification of the KSF that deriving from strategic priorities, the compilation of the strategic priorities for all 28 automotive suppliers gave the following areas:

1. The customer orientation through its satisfaction 
2. Improving the efficiency of production systems by optimizing resources and increase in capacity.

3. Maintaining a favorable climate and internal staff accountability

4. The adoption of quality standards (ISO TS 16949), quality control and cost reduction of non-quality to achieve Total Quality Management (TQM)

5. Improving Health and Safety

6. Development of human skills

Then to keep the consistency of our approach, we correlated our KSF expressed in strategic orientations with the KPIs that are already choosed by those companies. Then, the KPIs are adapted by the PMQ to choose the appropriate KPI (AKPI) for the overall performance.

The identification of AKPI has been matched by a hierarchical approach in the form of a survey organized in 3 parts:

1. What are the company managers to ask?

2. What is the priority for progress in the long term and what is the pertinence of existing indicators?

3. What are the actual goals and measurements?

Therefore, the PMQ was filled in by the General Managers of those plants in order to respect the first requirement of the PMQ method. For the second and third part, priorities for improvement were identified over the long term goal of the Moroccan automotive sector and by checking the relevance of existing indicators objectives. In the last, the PMQ's treatment proposes appropriate KPI (AKPI) as shown in the table 2.

Table 2. Treatment of KPI in the Moroccan's automotive suppliers, according to PMQ

\begin{tabular}{|c|c|c|c|c|c|c|c|c|c|c|c|c|c|c|}
\hline & \multicolumn{6}{|c|}{$\begin{array}{c}\text { Relevance KPIs existing / } \\
\text { improvement }\end{array}$} & KSF & \multirow[t]{2}{*}{ KPI } & \multicolumn{6}{|c|}{$\begin{array}{c}\text { Priority for long term } \\
\text { improvement }\end{array}$} \\
\hline & Null & & & $\gg>$ & & igh & & & & Null & & $\gg>$ & High & \\
\hline 1 & 2 & 3 & 4 & 5 & 6 & 7 & Customer orientation & Rate of Customer complaint & $\begin{array}{l}1 \\
7\end{array}$ & 2 & 3 & 4 & 5 & 6 \\
\hline 1 & 2 & 3 & 4 & 5 & 6 & 7 & & Cost of non-quality & $\begin{array}{l}1 \\
7\end{array}$ & 2 & 3 & 4 & 5 & 6 \\
\hline 1 & 2 & 3 & 4 & 5 & 6 & 7 & Total Quality & $\begin{array}{l}\text { Scrap rate } \\
\text { (Quality ppm) }\end{array}$ & $\begin{array}{l}1 \\
7\end{array}$ & 2 & 3 & 4 & 5 & 6 \\
\hline 1 & 2 & 3 & 4 & 5 & 6 & 7 & & Customer return rate & $\begin{array}{l}1 \\
7\end{array}$ & 2 & 3 & 4 & 5 & 6 \\
\hline 1 & 2 & 3 & 4 & 5 & 6 & 7 & & Service rate & $\begin{array}{l}1 \\
7\end{array}$ & 2 & 3 & 4 & 5 & 6 \\
\hline 1 & 2 & 3 & 4 & 5 & 6 & 7 & & Average cycle Time & $\begin{array}{l}1 \\
7\end{array}$ & 2 & 3 & 4 & 5 & 6 \\
\hline 1 & 2 & 3 & 4 & 5 & 6 & 7 & & Production volume & $\begin{array}{l}1 \\
7\end{array}$ & 2 & 3 & 4 & 5 & 6 \\
\hline 1 & 2 & 3 & 4 & 5 & 6 & 7 & & Process performance & $\begin{array}{l}1 \\
7\end{array}$ & 2 & 3 & 4 & 5 & 6 \\
\hline 1 & 2 & 3 & 4 & 5 & 6 & 7 & Efficiency of production systems & Machine availability & $\begin{array}{l}1 \\
1 \\
7\end{array}$ & 2 & 3 & 4 & 5 & 6 \\
\hline 1 & 2 & 3 & 4 & 5 & 6 & 7 & & Rate machine shuts down & $\begin{array}{l}1 \\
7\end{array}$ & 2 & 3 & 4 & 5 & 6 \\
\hline 1 & 2 & 3 & 4 & 5 & 6 & 7 & & $\begin{array}{l}\text { Mean Time Between Failures } \\
\text { (MTBF) }\end{array}$ & $\begin{array}{l}1 \\
7\end{array}$ & 2 & 3 & 4 & 5 & 6 \\
\hline 1 & 2 & 3 & 4 & 5 & 6 & 7 & & Cost of repairs & $\begin{array}{l}1 \\
7\end{array}$ & 2 & 3 & 4 & 5 & 6 \\
\hline 1 & 2 & 3 & 4 & 5 & 6 & 7 & & Absenteeism & 1 & 2 & 3 & 4 & 5 & 6 \\
\hline 1 & 2 & 3 & 4 & 5 & 6 & 7 & Internal climate favorable & Turn over & $\begin{array}{l}7 \\
1 \\
7\end{array}$ & 2 & 3 & 4 & 5 & 6 \\
\hline
\end{tabular}




\begin{tabular}{|c|c|c|c|c|c|c|c|c|c|c|c|c|c|c|}
\hline & \multicolumn{6}{|c|}{$\begin{array}{c}\text { Relevance KPIs existing / } \\
\text { improvement }\end{array}$} & KSF & KPI & \multicolumn{6}{|c|}{$\begin{array}{l}\text { Priority for long term } \\
\text { improvement }\end{array}$} \\
\hline & $\mathrm{Nul}$ & & & $\gg>$ & & igh & & & & Null & & $>>$ & High & \\
\hline \multirow[t]{2}{*}{1} & 2 & 3 & 4 & 5 & 6 & 7 & & Discipline & 1 & 2 & 3 & 4 & 5 & 6 \\
\hline & & & & & & & & & 7 & & & & & \\
\hline \multirow[t]{2}{*}{1} & 2 & 3 & 4 & 5 & 6 & 7 & Health and Safety & Number of Occupational & 1 & 2 & 3 & 4 & 5 & 6 \\
\hline & & & & & & & Health and Safety & Injuries & 7 & & & & & \\
\hline \multirow[t]{2}{*}{1} & 2 & 3 & 4 & 5 & 6 & 7 & Develonment of human skills & Training Days per Person & 1 & 2 & 3 & 4 & 5 & 6 \\
\hline & & & & & & & Development or human skills & & 7 & & & & & \\
\hline
\end{tabular}

In the light of the KPI treatment, we matched the AKPI through the KSF in the table 3:

Table 3. Identification of AKPI for each KSF of Moroccan automotive suppliers

\begin{tabular}{ll}
\hline KSF & AKPI \\
\hline Customer Orientation & Rate of Customer Complaint (Cc) \\
Total Quality & Scrap Rate (Qs) \\
Efficiency of Production Systems & Machine Availability (Ma) \\
Internal Climate Favorable & Absenteeism (Ab) \\
Health and Safety & Number of Occupational Injuries (Oi) \\
Development of Human Skills & Training Days per Person (Tdb) \\
\hline
\end{tabular}

\subsubsection{Weight Estimation of AKPI}

We have already identified 6 AKPI (Cc; Qs; Ma; Ab; Oi; Tdb) that are used in the calculation of the overall performance. In fact, each AKPI are coupled with the appropriate weight $\left(r_{1}, r_{2}, r_{3}, r_{4}, r_{5}, r_{6}\right.$ respectively). This association leads us to adopt the AHP method that allows AKPIs to be compared in pairs to define their relative importance through expert judgment. Then each AKPI is assigned an absolute importance (weight) based on previous respective importance on a scale ratio, with the constraint that these weights sum up to 1 . The AHP method is currently the most common method used in the industrial application to aggregate performance expressions. The outranking method compares the different criteria in five levels of importance to global satisfaction: "equal", "low", "critical", "proven" and "absolute" respectively quantified at 1, 3, 5, 7 and 9. Intermediate values between two levels are accepted (Clivelle, 2004). The experts assign an intensity number that represents the true preference of each reason with respect to other reasons. The intensity importance of factor $\mathrm{i}$ over factor $\mathrm{j}$ is equal to $\mathrm{a}_{\mathrm{ij}}$, and the intensity importance of factor $\mathrm{j}$ over $\mathrm{I}$ is equal to $1 / \mathrm{a}_{\mathrm{ij}}$. If we have $\mathrm{n}$ factors to compare, we develop $a_{n} n * n$ matrix A to represent the importance of these factors:

$$
\left(\begin{array}{ccc}
a_{1 n} & \ldots & a_{1 n} \\
\vdots & \ddots & \vdots \\
a_{n 1} & \cdots & a_{n n}
\end{array}\right)=\mathrm{A}
$$

Where $\mathrm{n}$ is the order of the matrix

To determine the weight for each AKPI, interviews of experts (General Managers, Leaders of the Moroccan Association of Automotive industry) in the Moroccan automotive industry were performed using pairwise comparisons between AKPIs.

In other terms, the weight between AKPI was explored on the base of the reply of the interviewers in the PMQ that were given 13 pairwise comparisons as shown in table 4 . 
Table 4. Pairwise comparison matrix

\begin{tabular}{|c|c|c|c|c|c|c|}
\hline$a_{i j}$ & $\mathrm{Cc}$ & Qs & $\mathrm{Ma}$ & $\mathrm{Ab}$ & $\mathrm{Oi}$ & $\mathrm{Tdb}$ \\
\hline$\overline{\mathrm{Cc}}$ & 1 & $1 / 4$ & $1 / 7$ & 5 & 6 & $1 / 5$ \\
\hline Qs & 4 & 1 & $1 / 4$ & 6 & 7 & $1 / 2$ \\
\hline $\mathrm{Ma}$ & 7 & 4 & 1 & 8 & 9 & 3 \\
\hline $\mathrm{Ab}$ & $1 / 5$ & $1 / 6$ & $1 / 8$ & 1 & 5 & $1 / 7$ \\
\hline Oi & $1 / 6$ & $1 / 7$ & $1 / 9$ & $1 / 5$ & 1 & $1 / 8$ \\
\hline $\mathrm{Tdb}$ & 5 & 2 & $1 / 3$ & 7 & 8 & 1 \\
\hline$\sum^{n} a$ & 17,4 & 7,56 & 1,96 & 27,2 & 36,0 & 4,97 \\
\hline
\end{tabular}

Table 5 represents the matrix $A_{1}$ as the normalized comparison matrix that is calculated as shown below:

$$
\left(\begin{array}{ccc}
a_{1 n}^{\prime} & \ldots & a_{1 n}^{\prime} \\
\vdots & \ddots & \vdots \\
a_{n 1}^{\prime} & \cdots & a_{n n}^{\prime}
\end{array}\right)=\mathrm{A}_{1} \text { and } a^{\prime}=\frac{a_{i j}}{\sum_{i, j=1}^{n} a_{i j}} \quad \text { for } i, j=1,2, \ldots, n \text {, }
$$

Table 5. Matrix $\mathrm{A}_{1}$

\begin{tabular}{|c|c|c|c|c|c|c|}
\hline$a^{\prime}{ }_{i j}$ & $\mathrm{Cc}{ }^{\prime}$ & Qs' & Ma' & $\mathrm{Ab}$ & Oi' & Tdb' \\
\hline$\overline{\mathrm{Cc}}$ & $(1) / 17,4$ & $(1 / 4) / 7,56$ & $(1 / 7) / 1,96$ & $(5) / 27,2$ & (6)/36 & $(1 / 5) / 4,97$ \\
\hline Qs' & $(4) / 17,4$ & (1)/7,56 & $(1 / 4) / 7,56$ & (6)/27,2 & $(7) / 36$ & $(1 / 2) / 4,97$ \\
\hline Ma' & $(7) / 17,4$ & $(4) / 7,56$ & (1)/7,56 & (8)/27,2 & $(9) / 36$ & (3)/4,97 \\
\hline $\mathrm{Ab}$ & $(1 / 5) / 17,4$ & $(1 / 6) / 7,56$ & $(1 / 8) / 7,56$ & $(1) / 27,2$ & $(5) / 36$ & $(1 / 7) / 4,97$ \\
\hline Oi' & $(1 / 6) / 17,4$ & $(1 / 7) / 7,56$ & $(1 / 9) / 7,56$ & $(1 / 5) / 27,2$ & (1)/36 & $(1 / 8) / 4,97$ \\
\hline Tdb' & $(5) / 17,4$ & (2)/7,56 & $(1 / 3) / 7,56$ & $(7) / 27,2$ & $(8) / 36$ & (1)/4,97 \\
\hline
\end{tabular}

The table 6 calculates the eigenvalue and the eigenvector

$$
\left(\begin{array}{l}
w_{1} \\
w_{2} \\
\vdots \\
w_{n}
\end{array}\right)=w \quad \text { and } \omega \mathfrak{t}=\frac{\sum_{i, j=1}^{n} a_{i j}^{\prime}}{n} \quad \text { for } i, j=1,2, \ldots, n
$$

The respective weight of each AKPI $\left(r_{1}, r_{2}, r_{3}, r_{4}, r_{5}, r_{6}\right)$ is given in table 5:

\begin{tabular}{|c|c|c|c|c|c|c|c|c|c|}
\hline$a^{\prime}{ }_{i j}$ & $\mathrm{Cc}^{\prime}$ & Qs' & Ma' & $\mathrm{Ab}$ & Oi' & $\mathrm{Tdb}$ & $a_{i j}^{\prime}$ & $\frac{l, J=1}{n}$ & Weight $\left(w_{i}\right)$ \\
\hline Cc' & 0,06 & 0,03 & 0,07 & 0,18 & 0,17 & 0,04 & 0,55 & $(0,55) / 6$ & 0,09 \\
\hline Qs' & 0,23 & 0,13 & 0,13 & 0,22 & 0,19 & 0,10 & 1,01 & $(1,01) / 6$ & 0,17 \\
\hline Ma' & 0,40 & 0,53 & 0,51 & 0,29 & 0,25 & 0,60 & 2,59 & $(2,59) / 6$ & 0,43 \\
\hline $\mathrm{Ab}$ & 0,01 & 0,02 & 0,06 & 0,04 & 0,14 & 0,03 & 0,30 & $(0,30) / 6$ & 0,05 \\
\hline Oi’ & 0,01 & 0,02 & 0,06 & 0,01 & 0,03 & 0,03 & 0,15 & $(0,15) / 6$ & $\mathbf{0 , 0 2}$ \\
\hline Tdb' & 0,29 & 0,26 & 0,17 & 0,26 & 0,22 & 0,20 & 1,40 & $(1,40) / 6$ & 0,23 \\
\hline
\end{tabular}

Table 6. Determination of AKPIs' weight

Figure 2 shows the importance of each weight, in fact, the weight of machine availability was the highest with a value of 0,43, followed by the weight of Development of Human Skills with 0,23. 


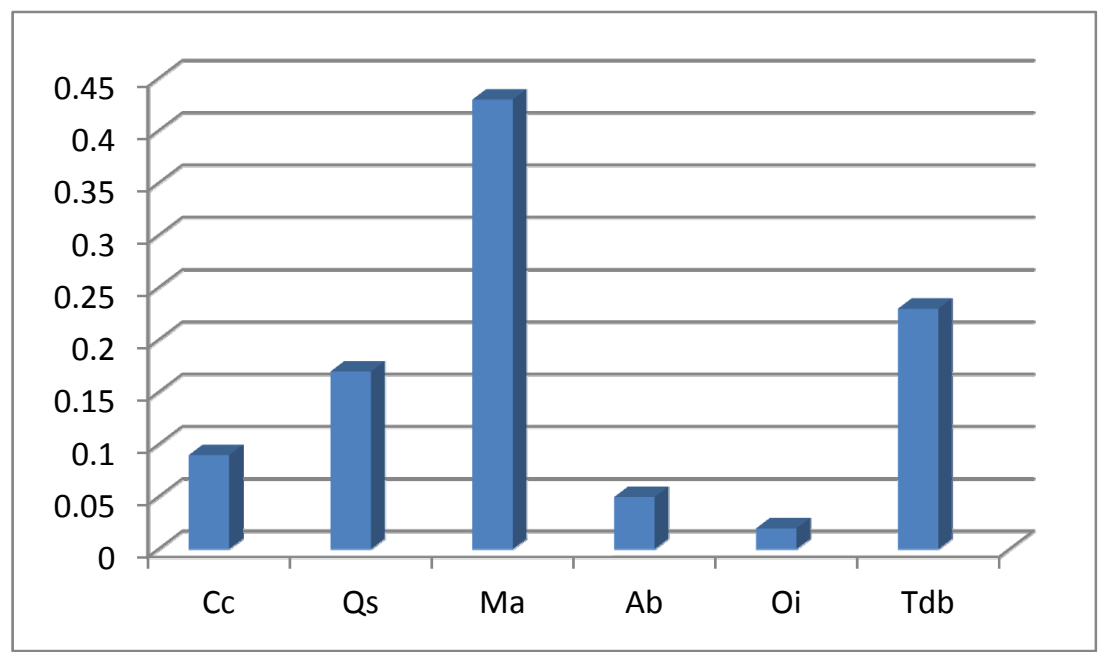

Figure 2. AKPI weight analysis

Figure 2 shows that the paradigm of the Moroccan automotive industry is the improvement of materials and the availability of manpower; also, the safety at work and the internal climate are integrated in the overall performance of these manufactories.

Traditionally, most plant managers focused on the triangle of (Cost, Quality and Delay). Subsequently, our model shows that there are other Key Factor of Success (Training, internal climate and Safety) which should be integrated in their strategic, tactical and operational management.

\subsubsection{AKPI Score Estimation}

Generally, KPIs are classified into quantitative and qualitative indicators. Quantitative ones represent performance in numbers, although qualitative performance indicator needs to be calculated to measure performance (Lee et al., 2013). So, each AKPI is associated with their estimate methods as is shown in the table 7:

Table 7. AKPIs calculation methods

\begin{tabular}{|c|c|}
\hline AKPI & Calculation methods \\
\hline $\mathrm{Cc}$ & $\begin{array}{l}\text { The number of customer complaints/ one million hours } \\
\text { delivered }\end{array}$ \\
\hline Qs & $\begin{array}{l}\text { (Non- conformities total / Parts supplied }) * 1 \text { Million }= \\
\text { PPM Quality } \\
\text { PPM Quality/ one million hours delivered }\end{array}$ \\
\hline $\mathrm{Ma}$ & $\begin{array}{l}\text { Ratio between the actual production time and the total } \\
\text { time available. }\end{array}$ \\
\hline $\mathrm{Ab}$ & Number of hours missed/ one million hours delivered \\
\hline Oi & $\begin{array}{l}\text { Number of Occupational Injuries (AT) / one million } \\
\text { hours delivered }\end{array}$ \\
\hline $\mathrm{Tdb}$ & $\begin{array}{l}\text { Average number of days of training per employee/one } \\
\text { million hours delivered }\end{array}$ \\
\hline
\end{tabular}

The global performance (GP) is expressed through AKPI's performance (PAKPI); the PAKPI is obtained by matching the Achievement Level (AL) through the percentage formula value measured of AKPI and the target value. Those PAKPI are expressions of criteria satisfaction through the percentage between the current value and the target value for each AKPI. These target values were established by the interviewers for each KPI that are given in Table 8: 
Table 8. AKPIs target values

\begin{tabular}{ll}
\hline $\mathrm{AKPI}$ & Target Percentage values \\
\hline $\mathrm{Cc}$ & $1 \%$ \\
$\mathrm{Qs}$ & $1 \%$ \\
$\mathrm{Ma}$ & $95 \%$ \\
$\mathrm{Ab}$ & $1 \%$ \\
$\mathrm{Oi}$ & $0,1 \%$ \\
$\mathrm{Tdb}$ & $0,02 \%$ \\
\hline
\end{tabular}

$\mathrm{P}_{\mathrm{AKPI}}$ is obtained by matching AL through the table 9:

Table 9. Calculating value of $\mathrm{P}_{\mathrm{AKPI}}$

\begin{tabular}{ll}
\hline $\mathrm{P}_{\text {AKPI }}$ Value & AKPI measured \\
\hline 1 & AKPI lower than target above $60 \%$ \\
0,95 & AKPI lower than target $41-60 \%$ \\
0,9 & AKPI lower than target $21-40 \%$ \\
0,85 & AKPI lower than target $6-20 \%$ \\
0,8 & AKPI equivalent to target $+/-5 \%$ \\
0,75 & AKPI higher than target $6-20 \%$ \\
0,7 & AKPI higher than target $21-40 \%$ \\
0,65 & AKPI higher than target $41-60 \%$ \\
0,6 & AKPI higher than target above $60 \%$ \\
\hline
\end{tabular}

The global performance (GP) is expressed in the formula below (Chen, 2008):

$$
G P=100 *\left(\mathrm{P}_{A K P I} * \sum_{i=1}^{6} r_{i}\right)
$$

Therefore, the formula for overall performance of Moroccan automotive suppliers is calculated as follows:

$$
G P=100 *\left(0,09 \mathrm{P}_{C c}+0,17 \mathrm{P}_{Q s}+0,43 \mathrm{P}_{M a}+0,05 \mathrm{P}_{A b}+0,02 \mathrm{P}_{O i}+0,23 \mathrm{P}_{T d b}\right)
$$

\subsection{Case Study}

To validate the applicability of the formula developed. We measured the global performance (GP) of a Moroccan automotive supplier A that belongs to studied companies according the sector's target.

The mean of this work is to give clarification about the global performance. This model consists in: analyzing the areas of actions, selecting the Key Success Factor, identifying the improvement factors, by the definition of Key Performance Indicators and the potential actions following their respective weight. Thus the global performance objective has been aggregated from the elementary expression (AKPI).

More specifically, Table 10 below gives, respectively, the AKPIs of the company September 2009, the associated measures, the achievement level and the score of each AKPI, in order to implement the model of the global performance's quantification.

In order to measure the performances of Company A against the sector's target, each AKPI were measured and examined in accordance with the target value applicable to each AKPI for calculating AKPI's performance. The score of each AKPI's performance was transformed to the intermediate score for each performance side. The performance aspect scores were then weighted in accordance with criteria specific to each aspect and converted to Global Performance (GP) score. 
Table 10. Calculating GP of Company A in September 2009

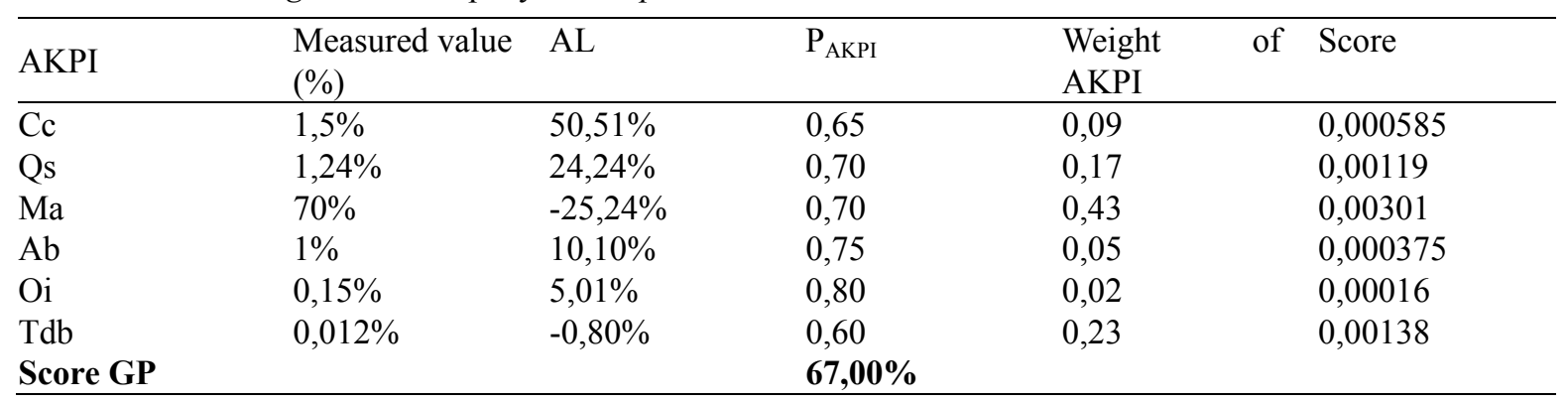

Company A received from the Moroccan government an amount of 400000 USD as support during the world financial crisis for the training of 700 employees, giving directly $0.011 \%$ as improvement of training's KPI.

After 30 months, the performance data were calculated in table 11:

Table 11. Calculating GP of Company A in March 2012

\begin{tabular}{llllll}
\hline AKPI & $\begin{array}{l}\text { Measured value } \\
(\%)\end{array}$ & AL & $P_{\text {AKPI }}$ & Weight of AKPI & Score \\
\hline $\mathrm{Cc}$ & $0,8 \%$ & $-20,20 \%$ & 0,85 & 0,09 & 0,000765 \\
$\mathrm{Qs}$ & $1,1 \%$ & $10,10 \%$ & 0,75 & 0,17 & 0,001275 \\
$\mathrm{Ma}$ & $90 \%$ & $-5,05 \%$ & 0,80 & 0,43 & 0,00344 \\
$\mathrm{Ab}$ & $0,6 \%$ & $-40,40 \%$ & 0,90 & 0,05 & 0,00045 \\
$\mathrm{Oi}$ & $0,09 \%$ & $-1,00 \%$ & 0,80 & 0,02 & 0,00016 \\
$\mathrm{Tdb}$ & $0,023 \%$ & $-1,77 \%$ & 0,80 & 0,23 & 0,00184 \\
Score GP & & & $\mathbf{7 9 , 3 0 \%}$ & & \\
\hline
\end{tabular}

\section{Results}

The overall performance of company A was 67\% in September 2009. And after training 700 employees, the global performance of the same company was 79,3\% in March 2012. This improvement seems to be explained by the improvement of the performance of training ( $\mathrm{Tdb}$ ) that moved from $0 ; 6$ to 0,8 . Also, we noticed a similar improvement $(+20 \%)$ of other AKPI's performance, such as customer complaint $(\mathrm{Cc})$ and absenteeism $(\mathrm{Ab})$.

The performance of Machine Availability (Ma) and Quality (Qs) seem to progress slowly (about $+10 \%$ ), whatever, despite of the progress of Safety's KPI (Oi), we noted that their performance were unchanged.

Otherwise, even the progress of Machine Availability's Performance was about 10\%, the score of this AKPI was the most important, followed by the score of training due to their high weights. Finally, the focus on the Machine Availability and Training should progress considerably the global performance of the company as exposed in figure 3:

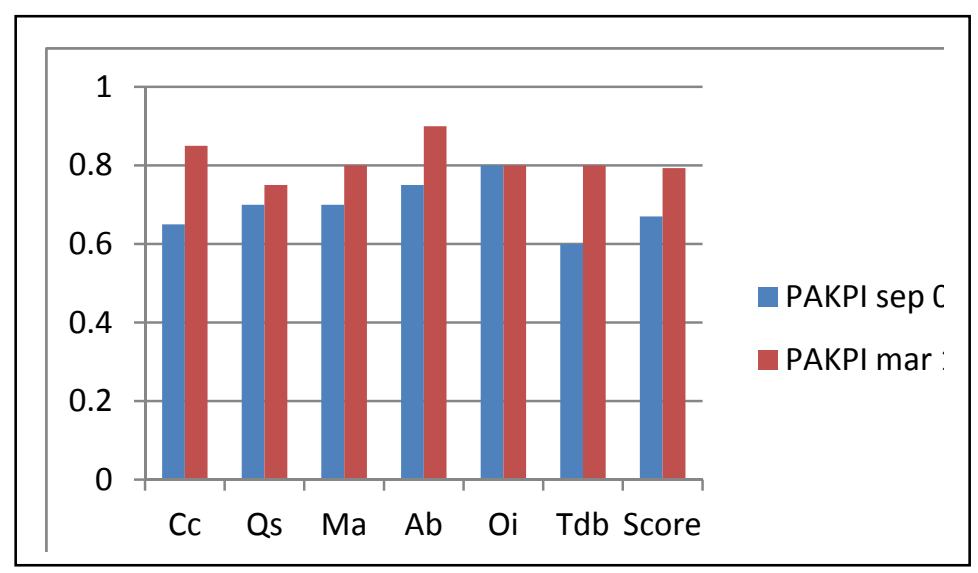

Figure 3. Performance data evolution of company A during September 2009-March 2012 
The final analysis of the results shows that the skill factors had impact positively on overall management performance. Therefore, the strategies of Corporation A should be focused on learning factors to improve management performance in the long term. That adjustment can substitute for other expensive strategies such whom concerning machines factors.

These measurements provide indications about for which the decision maker can reduce the investment because the business policy is too generous regarding a key factor or simply maintain investment because a satisfactory level has been reached at an optimal cost.

Once the required global performance progress is known, an important problem is the determination of the most "relevant" elementary performances to improve to reach the overall performance.

\section{Discussions}

An absence of state in performance measurement in Morocco was observed (AMICA, 2012). However the aim of this paper was to establish a performance measurement model in the most important manufacturing sector in Morocco.

All recent literature on PM agree with the need to develop traditional management accounting techniques that focused on the Iron Triangle (Time, Cost and Quality) which is not enough to cover all dimensions of manufacturer projects (Lauras et al., 2010). This model is a contribution to establishing a quantitative evaluation of performance in the Moroccan automotive industry compatible with world class standards and requirements.

The consequences concluded from this research are:

First of all, our model for the automotive industry applied the PMQ to choose the appropriate KPI (AKPI) for all the sector, and then those selecting the main KFS according to the results of the General Manager's interviews. The application of the AHP method allowed weighting AKPIs, and then the expression of overall performance was matched by using the association of Achievement Level (AL) with their weights; the results of this PM are accurate and systematic.

Second, the analyses of KSF/AKPI showed that the most important factors in the global performance of Moroccan automotive suppliers are the efficiency of production systems and Development of Human Skills.

Third, the analysis of the PMQ's results shows that the appropriate AKPIs (Cc; Qs; $\mathrm{Ma}$; $\mathrm{Ab}$; Oi; Tdb) are the most pertinent in the expression of overall performance. Hence, the Machine Availability and the training are most critical AKPI in the global performance.

Fourth, this model presents a generic method to be followed, allowing the Moroccan automotive suppliers to use in their strategic, tactical, and operational management.

\section{Conclusion}

This work gives us a complete view of performance measurement in the Moroccan automotive manufacturing sector by delivering an expression of their global performance. This PM model can be utilized to identify and select the best manufacturing practices on one hand, and to analyze the root of deficiency of each KSF/AKPI item after a simple measure on the other hand.

Furthermore, our model integrated all areas of improvements matched by the KSF; and it granted flexibility by combining performance parameters linearly in a manner to assist management in formulating the most suitable decision and strategy for several kinds of manufacturing projects.

However, this research did not treat the complex and dynamic interrelationships aspects between AKPIs. For further investigations, it is important to study those aspects.

\section{Acknowledgement}

We thank Mr. Abdelhak MOUNIR, leader of the Moroccan Association of Automotive Industry, Chairman of the Moroccan Institute for Training in Automotive Industry for his expertise in the preparation of this manuscript.

\section{References}

AMICA. (2012). Moroccan automotive sector. Moroccan Association of Automotive Industry, Casablanca, Morocco. Retrieved from http://www.unido.or.jp/download/AMICA-PRESENTATION_Japon.pdf

Aracioglu, B., Zalluhoglu, A. E., \& Candemir, C. (2013). Measuring and evaluating performance within the strategic management perspective: A study on performance measurement of a seafood company. Procedia-Social and Behavioral Sciences, 99, 1026-1034. http://dx.doi.org/10.1016/j.sbspro.2013.10.576

Berrah, L., \& Clivelle, V. (2007). Towards an aggregation performance measurement system model in a supply 
chain context. Computers in Industry, 58, 709-719. http://dx.doi.org/10.1016/j.compind.2007.05.012

Berrah, L., \& Foulloy, L. (2013). Towards a unified descriptive framework for industrial objective declaration and performance measurement. Computers in Industry, 64, 650-662. http://dx.doi.org/10.1016/j.compind.2013.03.006

Berrah, L., Mauris, G., \& Vernadat, F. (2004). Information aggregation in industrial performance measurement: rationales, issues and definitions. International Journal of Production Research, 42(20), 4271-4293. http://dx.doi.org/10.1080/00207540410001716534

Bititci, U. S., Suwignjo, P., \& Carrie, A. S. (2001). Strategy management through quantitative modeling of performance measurement system. International Journal of Production Economics, 69, 15-22. http://dx.doi.org/10.1016/S0925-5273(99)00113-9

Braz, R. G. F., Scavarda, L. F., \& Martins, R. A. (2011). Reviewing and improving performance measurement systems: An action research. International Journal of Production Economics, 133, 751-760. http://dx.doi.org/10.1016/j.ijpe.2011.06.003

Brimson, J. A. (1991). Activity Accounting, Editions John Wiley and Sons, New York. ISBN-. 0471539856

Carr, J. E., \& Hassan, M. (2008). An empirical study of performance measurement systems in manufacturing companies. Journal of achievements in materials and manufacturing engineering, 31(2), 616-621. Retrieved from www.journalamme.org/papers_vol31_2/31268.pdf

Chen, C. C. (2008). An objective-oriented and product-line based manufacturing performance measurement. International Journal of Production Economics, 112, 380-390. http://dx.doi.org/10.1016/j.ijpe.2007.03.016

Clivelle, V., Berrah, L., \& Mauris, G. (2006). Quantitative expression and aggregation of performance measurements based on the MACBETH multi-criteria method. International Journal of Production Economics, 105, 171-189. http://dx.doi.org/10.1016/j.ijpe.2006.03.002

Cliville, V. (2004). Systemic approach and multicriteria method for the definition of performance indicators system. Thesis for the degree of Doctor of Philosophy, Savoie University, Annecy, France. Retrieved from www.polytech.univ-savoie.fr/fileadmin/polytech_autres_sites/sites/listic/Theses/thesecliville.pdf

De Lima, E. P., Dacosta, S. E. G., Angelis, J. J., \& Munik, J. (2013). Performance measurement System: a consensual analysis of their roles. International journal of Production Economics, 146, 524-542. http://dx.doi.org/10.1016/j.jpe.2012.05.007

Ducq, Y., Vallespir, B., \& Doumeingts, G. (2001). Coherence analysis methods for production systems by performance aggregation. International Journal of Production Economics, 7, 23-37. http://dx.doi.org/10.1016/S0925-5273(00)00054-2

Eccles, R. G., (1991). The performance measurement manifesto. Harvard Business Review, 69, 131-137. http:/hbr.org/1991/01/the-performance-measurement-manifesto/ar/pr

Eswaramurthi, K. G., \& Mohanram, P. V. (2013). provement of manufacturing performance measurement system and evaluation of overall resource effectiveness. American Journal of Applied Sciences, 10(2), 131-138. http://dx.doi.org/10.3844/ajassp.2013.131.138

Folan, P., \& Browne, J. (2005). A review of performance measurement: Towards performance management. Computers in industry, 56, 663-680. http://dx.doi.org/10.1016/j.compind.2005.03.001

Folan, P., Browne, J., \& Jagdev, H. (2007). Performance: Its meaning and content for today's business research. Computers in industry, 58, 605-620. http://dx.doi.org/10.1016/j.compind.2007.05.002

Franco-Santos, M., Lucianetti, L., \& Bourne, M. (2012). Contemporary performance measurement systems: A review of their consequences and a framework for research. Management Accounting Research, 12, 79-119. http://dx.doi.org/10.1016/j.mar.2012.04.001

Ghalayini, A., Noble, J. S., \& Crowe, T. J. (1997). An integrated dynamic performance measurement system for improving manufacturing competitiveness. International journal of Production Economics, 48, 207-225. http://dx.doi.org/10.1016/S0925-5273(96)00093-X

Grigoroudis, E., Orfanoudaki, E., \& Zopounidis, C. (2012). Strategic performance measurement in a healthcare organization: a multiple criteria approach based on balanced scorecard. OMEGA, 40, 104-119. http://dx.doi.org/10.1016/j.omega.2011.04.001

Hernandez-Matias, J. C., Vizan, A., Perez-Garcia, J., \& Rios, J. (2008). An integrated modelling framework to 
support manufacturing system diagnosis for continuous improvement. Robotic and Computer integrated Manufacturing, 24, 187-199. http://dx.doi.org/10.1016/j.rcim.2006.10.003

Kaplan, R., \& Norton, D. (1996). The Balanced Scorecard: Translating Strategy into Action, Harvard Business School Press, Boston, 43-147. ISBN-0-87584-651-3.

Kennerley, M., \& Neely, A. (2003). Measuring performance in a changing business environment. International Journal of Operations and Production Management, 23(2), 229. http://dx.doi.org/10.1108/01443570310458465.

Kueng, P., \& Krahn, A. J. (1999). Building a process performance measurement system: Some early experiences. Journal of Scientific \& Industrial Research, 58(03-04), $149-159$. http://nopr.niscair.res.in/bitstream/123456789/17801/1/JSIR\%2058\%283-4\%29\%20149-159.pdf

Lauras, M., Marques, G., \& Gourc, D. (2010). Towards a multi-dimensional project performance measurement System. Decision Support Systems, 48, 342-353. http://dx.doi.org/10.1016/j.dss.2009.09.002

Lee, D., Kim, M., \& Kim, S. (2013). Management performance evaluation model of Korean construction firms. Journal of building construction and planning research, 1, 27-38. http://dx.doi.org/10.4236/jbcpr.2013.12005

Lohman, C., \& Fortuin, L. (2004). Designing a performance measurement system: a case study. European. Journal of Operational Research, 156, 267-286. http://dx.doi.org/10.1016/S0377-2217(02)00918-9

Marques, G., Gourc, D., \& Lauras, M. (2010). Multi-criteria performance analysis for decision making in project management. International Journal of Project Management, 29, 1057-1069. http://dx.doi.org/10.1016/j.ijproman.2010.10.002

Melnyk, S. A., Bititci, U. S., Platts, K., Tobias, J., \& Anderson, B. (2014). Is performance measurement and management fit for the future? Management Accounting Research, 25(2), $173-186$. http://dx.doi.org/10.1016/j.mar.2013.07.007

Michalska, J. (2005). The usage of the balanced scorecard for the estimation of the enterprise's effectiveness. Journal of materials processing technology, 162-163, $751-758$. http://dx.doi.org/10.1016/j.jmatprotec.2005.02.227

Micheli, P., \& Mari, L. (2014). The theory and practice of performance measurement. Management Accounting Research, 25(2), 147-156. http://dx.doi.org/10.1016/j.mar.2013.07.005

Neely, A. (1999). The performance measurement revolution: Why now and what next? International Journal of Operations \& Production Management, 19(2), 205-228. http://dx.doi.org/10.1108/01443579910247437

Neely, A., Mills, J., Platts, K., Gregory, M., \& Richards, H. (1996). Performance measurement design: Should process based approaches be adopted? International Journal of Production Economics, 46-47, 423-431. http://dx.doi.org/10.1016/S0925-5273(96)00080-1

Nudurupati, S. S., Bititici, U. S., Kumar, V., \& Chan, F. T. S. (2011). State of the art literature review on performance measurement. Computers \& Industrial Engineering, 60, 279-290. http://dx.doi.org/10.1016/j.cie.2010.11.010

Parmenter, D. (2007). Key Performance Indicators: Developing, Implementing, and Using Winning KPIs. John Wiley \& Sons, Inc., Hoboken, New Jersey, 2-3. ISBN-13: 978-0-470-09588-1

Popova, V., \& Sharpanskykh, A. (2011). Formal modeling of organizational goals based on performance indicators. Data \& Knowledge Engineering, 70, 335-364. http://dx.doi.org/10.1016/j.datak.2011.01.001

Rahman, M. N. A., Khamis, N. K., Zain, R. M., Deros, B. M., \& Mahmood, W. H. W. (2010). Implementation of $5 \mathrm{~S}$ practices in the manufacturing companies: A case study. American Journal of Applied Sciences, 7, 1182-1189. http://dx.doi.org/10.3844/ajassp.2010.1182.1189

Rodriguez, R. R., Saiz, J. J. A., \& Bas, A. O. (2009). Quantitative relationships between key performance indicators for supporting decision-making processes. Computers in Industry, 60(2), 104-113. http://dx.doi.org/10.1016/j.compind.2008.09.002

Subramanian, N., \& Ramanathan, R. (2012). A review of applications of Analytic Hierarchy Process in operations management. International Journal of Production Economics, 138, $215-241$. http://dx.doi.org/10.1016/j.ijpe.2012.03.036

Suwignjo, P., Bititci, U., \& Carrie, A. S. (2000). Quantitative models for performance measurement system. 
International Journal of Production $\quad$ Economics, $231-241$. http://dx.doi.org/10.1016/S0925-5273(99)00061-4

Vaidya, O. S., \& Kumar, S. (2006). Analytic hierarchy process: an overview of applications. European Journal of Operational Research, 169, 1-29. http://dx.doi.org/10.1016/j.ejor.2007.01.004

\section{Copyrights}

Copyright for this article is retained by the author(s), with first publication rights granted to the journal.

This is an open-access article distributed under the terms and conditions of the Creative Commons Attribution license (http://creativecommons.org/licenses/by/3.0/). 